\title{
Common Physical Barriers That Limit Access for Voters with Disabilities and Options to Solve Them
}

\author{
Jim Terry, Kaylan Dunlap, Steve Flickinger, \\ and Dan Woosley
}

\begin{abstract}
Successfully conducting an election requires that election administrators consider the diverse needs of their constituents and provide polling locations that allow those with disabilities to access the polling location and cast a ballot without encountering barriers. Having a working knowledge of the terminology and standards used to assess polling location accessibility can ensure that election administrators and poll workers are creating an environment that allows all voters to cast a ballot.
\end{abstract}

Keywords Accessibility $\bullet$ Americans with Disabilities Act $\bullet$ Polling locations

J. Terry $(\bowtie) \bullet$ K. Dunlap $\bullet$ S. Flickinger $\bullet$ D. Woosley Evan Terry Associates, LLC., Birmingham, AL, USA e-mail: jterry@evanterry.com

(C) The Author(s) 2019

M. Brown et al. (eds.), The Future of Election Administration, Elections, Voting, Technology, https://doi.org/10.1007/978-3-030-18541-1_26 
By the morning of an Election Day, a lot of hard work has gone into the preparation and set up of polling places. Ramps and platforms have been installed, signs have been hung, and steps have been taken to assure that every voter, regardless of disability, is able to easily and safely access their assigned voting areas. The problem is that things change during the busy voting day. Chairs and other obstacles are accidentally moved into the accessible routes, voting equipment gets bumped out of place, and signs are flipped around by the wind or blown down. Most of this happens unintentionally, but the fact remains that throughout the day, these changes lead to many polling places becoming inaccessible for some voters. In order to help visualize areas of concern, try to see the polling place as a voter with a disability might experience it. Try to anticipate what issues they might experience so that common problems can be identified and addressed, and poll workers will know what to do if these or other issues are encountered.

\section{Components of Accessibility}

\section{Accessible Routes}

The first concept to be understood is the "accessible route." The accessible route is a continuous unobstructed path connecting all accessible elements and spaces at the polling place. It is the easiest and safest route for people with mobility disabilities who use wheelchairs, scooters, or walkers to get around to everywhere they need to go in order to vote. Exterior accessible routes always include the sidewalks and walkways leading to the accessible entrance and may include parking access aisles, curb ramps, ramps, and sometimes an exterior lift.

Interior accessible routes include corridors or hallways and doorways plus certain aisles and clear floor spaces within the voting area. They may also include ramps, elevators, and platform lifts. One can imagine the accessible route as a "red carpet" that begins where a voter arrives and that allows them to get to every place they need to go so that they can vote. Of course, it is not visibly shown on the floor, but it could be.

The accessible route includes the route leading from the sidewalks and accessible parking to the accessible entrance. From there, visualize the accessible route going down the corridors and into the voting area. Once inside the voting area, the accessible route leads to all the various stops in the voting process. From the site entrance to any voter information and translators' tables (if provided), to the voter registration check in tables, on to the ballot 
marking device (if employed), and the American with Disabilities Act (ADA) accessible privacy booth, then to the scanners, and back out to the exit. This "red carpet" accessible route has to be free from obstructions such as steps, overgrown landscaping, trash cans, furniture, boxes, and anything else that might block someone who is trying to follow the accessible route. The accessible route does not have to be physically marked in any way, but it has to be provided and it has to be kept clear at all times.

Although 4 or 5 feet of clear width is preferred, accessible routes must always be at least 36 inches wide, with one exception. The route can narrow to as little as 32 inches for no more than 24 inches ( 2 feet) in distance at a time. An example might be a doorway that is 32 inches wide or a place where a column narrows the route. This minimum width will allow someone using a wheelchair the opportunity to push themselves through the narrow space without hitting their hands or elbows. But again, it can only be as narrow as 32 inches and can continue for no more than 24 inches (2 feet) at a time. If something moveable narrows the width for more than that 24-inch segment, move the obstruction to provide the full 36 inches of width along that part of the accessible route. While you are checking the corridors, also check to make sure that all of the doorways on the accessible route are propped open with nothing blocking access or reducing the clear width to less than 32 inches. For example, make sure that no one props a door open with a trash can, cone, brick, or large stone. A propped door may be helpful, but if it is done with an object that narrows the clear width, the object itself becomes an obstacle.

While this accessible route will have been set up at the beginning of the day, a poll worker should be assigned the task of walking the accessible route at least every two hours using the Department of Justice $A D A$ Checklist for Polling Places to make sure accessibility is maintained throughout the day and to make sure that these clearances are still provided. ${ }^{1}$ If you find anything obstructing the accessible route, move it immediately (Figs. 26.1 and 26.2).

\section{Circulation Path}

Like voters with mobility disabilities who use the accessible route, voters who are blind or with low vision will use what is called the "circulation path." The circulation path includes the accessible route but is much

\footnotetext{
${ }^{1}$ Accessible at https://www.ada.gov/votingck.htm.
} 


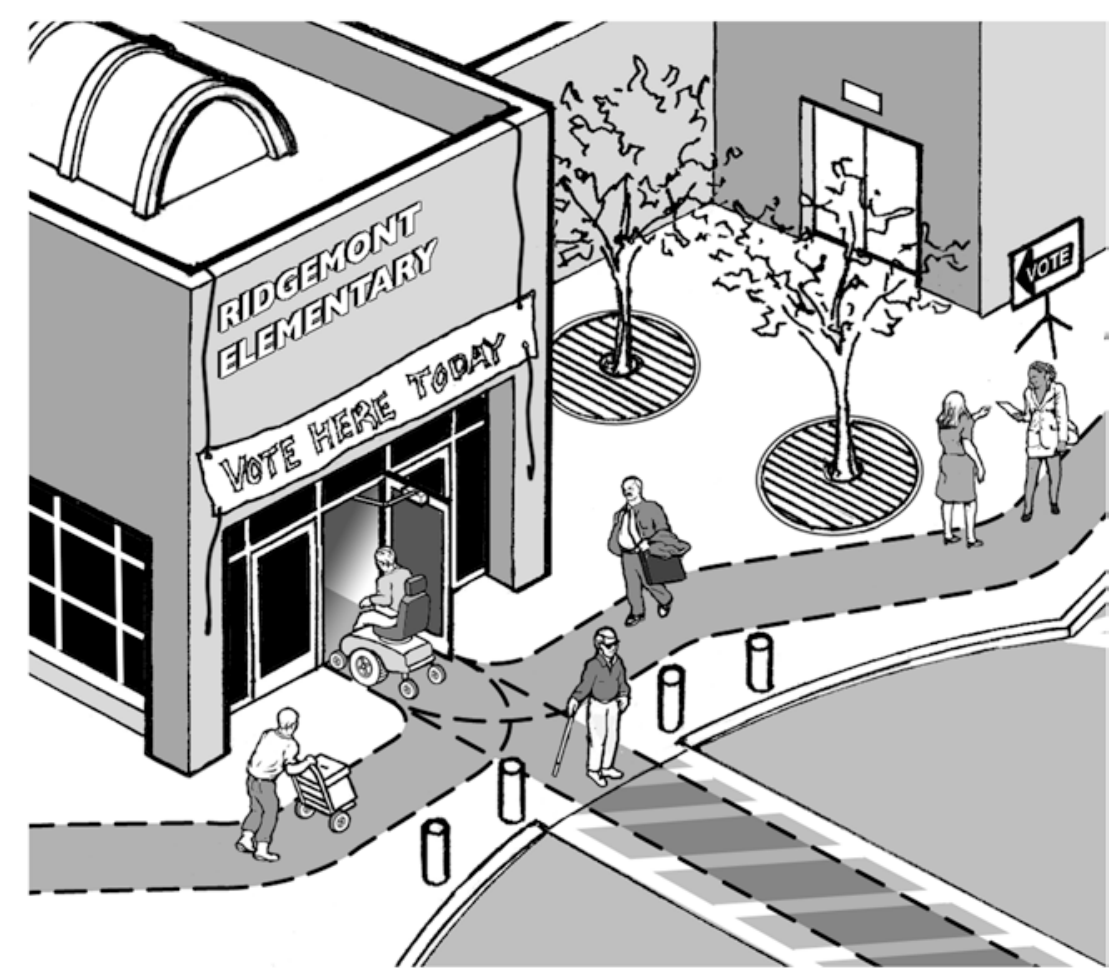

Fig. 26.1 Accessible polling location

bigger than that. Usually, the circulation path includes all of the areas where voters can walk. It also includes the headroom above the walking surface up to the height of 80 inches. Many polling places have protruding objects that are more than 27 inches above the floor, and less than 80 inches above the floor where they're above the voters' heads. If these objects are within this zone between 27 and 80 inches above the floor and they hang off of the wall more than 4 inches into the circulation path, they can be a problem because these objects will not be cane-detectable by someone who is blind or who has low vision.

Places where headroom is less than 80 inches above the floor can also create similar problems for voters who have vision loss. Features that can be detected with a white cane can be placed below these hazards. Fixed objects or items such as orange cones that are provided by the Board 


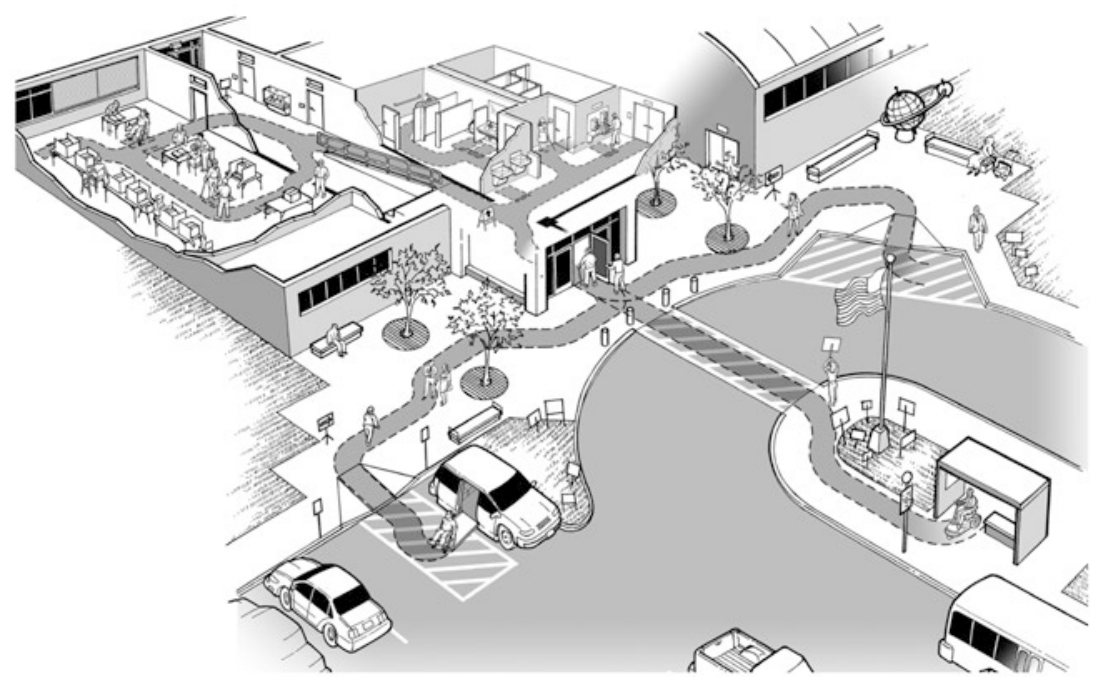

Fig. 26.2 Accessible routes

of Elections can be placed below protruding objects to prevent accidental injury to voters who are blind or have low vision.

Imagine a voter who is blind walking with a cane who encounters a large coat rack or a protruding bookshelf that is hung high on the wall. That coat rack or shelf would not be cane-detectable and could injure that voter. Some of the worst problems identified during accessibility surveys of polling places include big wall-mounted fire extinguishers, air conditioners hanging over entrance walkways or ramps, stairways with open undersides, equipment brackets and controls in school gymnasiums, and pipes hanging too low in unexpected places. Sometimes temporary scaffolding has large open areas near the ground that are not cane-detectable and that are situated along the accessible route or circulation path. Those open areas will need low horizontal straps or orange cones so that people using canes don't mistake those openings for a walkway.

If placing a cane-detectable element like an orange cone under a protruding object would narrow the required accessible route to less than 36 or 32 inches wide and there is no other solution to protect voters who are blind or have low vision, a poll worker, sometimes referred to as an accessibility clerk, should be stationed there to warn people to watch their 
heads. As maintenance rounds are conducted every two hours, the monitor should make sure these features have not been moved and are still correctly protecting the voters from these head and arm bangers. For what it is worth, the cones will also help voters who are looking down at their smartphones or just not paying enough attention to where they are walking.

Once the accessible route is clear from any obstruction and areas with low headroom and protruding objects are protected, a search for floor obstructions will be necessary to ensure that any electrical cords in voter areas are not tripping hazards. When the voting area is crowded, extension cords that cross voter areas may be hard to see, so they should always be covered with a thick mat or securely taped down wherever the voters will walk across them. It is also best practice to run any power cables outside of the 5 foot by 5 foot clear floor areas on the voter sides of accessible voting equipment to make turning around in those areas easier for everyone, including walker, scooter, manual wheelchair, and power chair users.

By paying close attention to these important details, these kinds of issues can and will be identified and corrected before they become major problems during the day. Then everyone will be able to vote on Election Day without encountering these common barriers to accessibility.

Open Access This chapter is licensed under the terms of the Creative Commons Attribution 4.0 International License (http://creativecommons.org/licenses/ by $/ 4.0 /)$, which permits use, sharing, adaptation, distribution and reproduction in any medium or format, as long as you give appropriate credit to the original author(s) and the source, provide a link to the Creative Commons licence and indicate if changes were made.

The images or other third party material in this chapter are included in the chapter's Creative Commons licence, unless indicated otherwise in a credit line to the material. If material is not included in the chapter's Creative Commons licence and your intended use is not permitted by statutory regulation or exceeds the permitted use, you will need to obtain permission directly from the copyright holder.

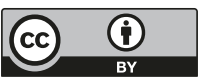

